\title{
Military ombudsman to again review mental health services
}

Published at www.cmaj.ca on Mar. 29

$\mathrm{N}$ ational Defence and Canadian Forces Ombudsman Pierre Daigle will conduct a followup review of a 2008 investigation into military mental health services that found that too many soldiers with operational stress injuries (OSIs) were slipping through cracks in the system.

Though the Canadian military has improved its mental health system since 2008, several problem areas remain, says Darren Gibb, director of communications for Daigle's office. One of the biggest concerns, he says, is that families of military members affected by mental illness are not receiving proper care.

"The programs just don't exist for military families, and if they do exist, they are inconsistent across the country," says Gibb. "Programs are in place for Canadian Forces members, but not adequately so for families."

Another major concern, he says, is the lack of progress in gathering information and statistics about current and former military members affected by mental illness. "You can't ensure you are capturing all people suffering from operational stress injuries if you don't have a database. We would like to see more progress on that," says Gibb. "We have been calling on them to do that since 2002."

The first ombudsman investigation into the state of the military's mental health services was launched in response to a complaint made a former soldier, Corporal Christian McEachern, who was facing criminal charges for driving a vehicle through the entrance of the garrison headquarters at CFB Edmonton in Alberta (www.ombudsman.forces.gc.ca /rep-rap/sr-rs/pts-ssp/index-eng.asp).

McEachern, who was released from duty on July 23, 2001, had been suffering from post-traumatic stress disorder (PTSD) and claimed the military had not treated him fairly.

The investigation led to a February 2002 report, Systemic treatment of $C F$

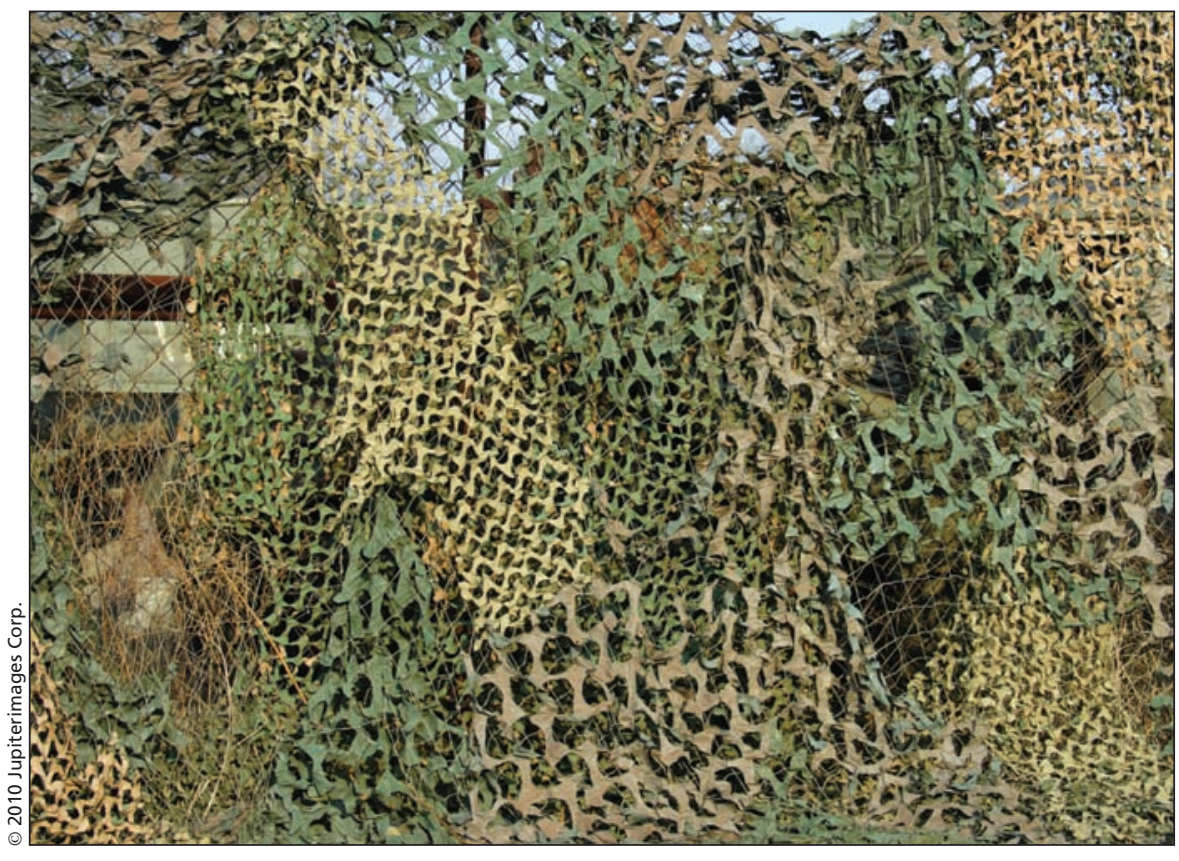

Soldiers can be medically released for mental health injuries, as they could be if physical injuries made them unable to serve, but all information regarding care is confidential, says Lieutenant Colonel Dr. Rakesh Jetly.

members with PTSD, in which thenombudsman André Marin concluded that McEachern's complaints were justified: "As is the case for many $\mathrm{CF}$ [Canadian Forces] members who suffer from PTSD, he was stigmatized and isolated from his unit, without the support from his peers that could have sustained him," the report states. The investigators also concluded that the issues raised by McEachern were not isolated but rather "systemic in nature."

The report made 31 recommendations on how to better identify and treat PTSD in the military. Those included national tracking of military members affected by mental illness, establishing awareness and education campaigns, helping reduce stress and burnout among caregivers, accelerating efforts to standardize treatment, determining an effective means of reintegrating post-deployment soldiers into family life and improving support programs for military family members affected by PTSD.
Marin acknowledged that the Canadian Forces had taken great strides in the preceding years to better care for its members suffering from post-traumatic stress disorders. But much more needed to be done, he concluded. "I realize that placing more demands on resources is something much easier said than done in these difficult and uncertain economic times," he stated in the report. "However, if such resources are not made available now, the long-term costs to the CF as a whole will be immeasurable."

Less than a year later, Marin released a follow-up report, Review of DND/CF Actions on Operational Stress Injuries, that made note of a significant increase in the awareness of mental health injuries and of several new military programs established to deal with such injuries (www.ombudsman.forces .gc.ca/rep-rap/sr-rs/fr-rs/index-eng.asp).

But Marin also found that in other areas - such as outreach, training and data collection — little progress had 
been made. He also expressed concern that unless the treatment of operational stress injuries improved, many soldiers that could have remained in the military would be dismissed.

"I am particularly concerned that, in an era where recruitment and retention is an issue, valuable and productive $\mathrm{CF}$ members are still being unnecessarily lost," he stated. "Many see OSI as a one-way ticket out of the CF."

Six years later, the ombudsman's office again looked into how the Canadian Forces had progressed in addressing operational stress disorders and again found progress lacking in certain areas. In December 2008, then-interim ombudsman Mary McFadyen released a second follow-up report, A Long Road to Recovery: Battling Operational Stress Injuries, in which she noted that 18 of the original recommendations had not been fully implemented, particularly those related to leadership, governance, data collection and monitoring (www .ombudsman.forces.gc.ca/rep-rap/sr-rs /osi-tso-3/rep-rap-01-eng.asp\#int).

"The consequences for individuals who fall through the cracks are often devastating and long lasting," McFadyen stated. "Although the Department and the Canadian Forces have made progress in identifying, preventing and treating post-traumatic stress disorder and other operational stress injuries within Canada's Defence community, it is clear that more needs to be done."

McFadyen urged the Canadian Forces to implement "the intent" of Marin's original 31 recommendations. Her report highlighted nine recommendations to address "current realities and current problems" regarding operation stress injuries, including developing a database to accurately reflect the number of active and reserve military members affected by stress-related injuries, creating a full-time position for a national operational stress injury coordinator, conducting an independent and confidential mental health survey, assessing the need for additional mental health care professionals and implementing a national program to prevent stress and burnout in the mental health care community.
The forthcoming investigation will be the third ombudsman's follow-up to the original 2002 investigation.

Though shortcomings remain, Gibb says that the Canadian Forces has made much progress in the area of mental health in recent years. "Even though we are critical of the Canadian Forces, they have come along way in 10 years," he says.

The progress is the product of a significant investment in mental health, says Lieutenant-colonel Dr. Rakesh Jetly, a psychiatrist and a senior mental health adviser for the military. There have been many positive changes, says Jetly, including a new emphasis on placing mental health professionals in teams to better meet the needs of soldiers, from diagnosis to treatment to follow-up.

"Over the last 10 years, we went from a discipline-specific approach to a team approach in mental health," Jetley adds. "We introduced team-base care. We went from 240 to 440 people. Our teams have psychiatrists, psychologists, mental health nurses, social workers and chaplains. We have a mix of uniformed professionals, public servants and contractors."

There's been success in reducing the stigma surrounding mental health, says Jetly. The Canadian Forces has become a "mentally literate" organization because of the increased engagement of military leadership, he says. In September 2009, for instance, General Walt Natynczyk, the chief of defence staff, launched a mental health awareness campaign called "Be the Difference," to encourage all personnel to help those affected by mental illness.

"Now, what's incredible is that I think we are ahead of the curve when it comes to stigma," Jetly says.

He adds that one of the traditional barriers to receiving mental health care in the military has been ignorance of the mental conditions that require care. But that has been greatly reduced by a push to better educate soldiers about mental health, Jetly says. The Canadian Forces recently created a system-wide mental health educational campaign to teach soldiers about mental injuries, reduce stigma surrounding mental health problems and change attitudes about seeking help.

Another possible barrier to obtaining care is the fear that superiors will be made aware of their soldiers' mental problems, which many believe would have a negative impact on their military careers. But Jetly says that just as in the civilian world, where employers are not privy to information about the mental health care received by employees, this is not a problem. Though soldiers can be medically released for mental health injures, as they could be if physical injuries made them unable to serve, all information regarding care is confidential.

"Confidentiality is absolutely of paramount importance," says Jetly.

Another major initiative started this decade is the Operational Stress Injury Social Support Program, launched in 2001 to provide confidential peer support to Canadian Forces members, their families and veterans who are affected by such problems as anxiety, depression and post-traumatic stress disorder (www.osiss.ca). In the program's nineyear history, the veterans hired to serve as counsellors have assisted some 5000 people.

"Isolation is a toxin for mental health," says Lieutenant-colonel Stéphane Grenier, special adviser on operational stress injuries for the Canadian Forces and the driving force behind the program. "What this program is trying to do is find an antidote to the poison of isolation." - Roger Collier, CMAJ

DOI:10.1503/cmaj.109-3202

Editor's note: Third of a series on mental health and the military

Part 1: Where "stigma leaves the room" (CMAJ 2010.

DOI:10.1503/cmaj.109-3197)

Part 2: Veterans stepping forward for treatment of operational stress injuries (CMAJ 2010.

DOI:10.1503/cmaj.109-3213) 